\title{
OXYGEN DISTRIBUTION PROFILES IN THIN EVAPORATED CONTACTS ON SINGLE CRYSTAL SILICON
}

\author{
STURE PETERSSON, HERMAN NORDE \\ Institute of Technology, 75121 Uppsala, Sweden \\ G. POSSNERT and B. ORRE \\ Institute of Physics, 75121 Uppsala, Sweden
}

\begin{abstract}
The nuclear resonance in the ${ }^{16} \mathrm{O}(\alpha, \alpha)^{16} \mathrm{O}$ elastic scattering reaction at $3.045 \mathrm{MeV}$ has been used in concentration profile measurements of oxygen in thin-film structures.

The concentration profile can be deduced from an energy scan of the incoming $\alpha$-particles, thus shifting the resonance to different depths in the sample. The method has been applied to studies of the structures (a) an etched Si-surface, (b) $\mathrm{Au}$ evaporated on $\mathrm{Si}$, and (c) a Au-Ge-Si structure. Evidence is presented for the presence of oxygen in the Au layer and in the Ge layer.
\end{abstract}

\section{Introduction}

The electrical properties of metal-semiconductor contacts are strongly dependent on the nature of the interface between metal and semiconductor ${ }^{1,2}$ ). With respect to the formed interface barrier height it has been found that the interface oxide is probably the single most important property. These naturally formed oxide layers are of thickness in the range $10-50 \AA$.

It is also well known that some metal-semiconductor contacts, such as the $\mathrm{Au}-\mathrm{nSi}$ contact in standard surface barrier detectors, need a period of stabilization in air before the barrier has increased to its final value. It has also been shown that an oxygen backfill after the gold evaporation gives the best results when fabricating surface-barrier detectors ${ }^{3}$ ).

For investigation of the oxygen content in these contacts, there are besides conventional RBS analysis $\left.{ }^{4}\right)$ different useful techniques, such as the $(d, p)$ and $(p, \alpha)$ nuclear reactions $\left.{ }^{5}\right)$, the $(p, p)$ resonant proton scattering $\left.{ }^{6}\right)$, the $(\mathrm{d}, \alpha)$ nuclear reaction $\left.^{7}\right)$ and the $(\alpha, \alpha)$ resonance $\left.{ }^{8}\right)$. In this paper we have used the last mentioned: the ${ }^{16} \mathrm{O}(\alpha, \alpha)^{16} \mathrm{O}$ resonance at $3.05 \mathrm{MeV}$. The method has advantages over other techniques in the analysis of thin-layer

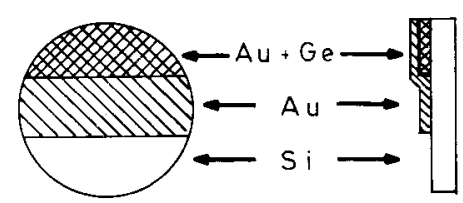

Fig. 1. Sample configuration. The substrate is etched single crystal silicon. structures, as the resonance is symmetric $\left.{ }^{8}\right)$ and moderately narrow, $(<20 \mathrm{keV})$ and the relatively high stopping power for $\alpha$-particles implies a comparatively good depth resolution. The sensitivity, however, is not as good as that obtained from nuclear reactions.

\section{Experimental}

\subsection{SAMPLE PREPARATION}

The investigated structures were made with standard etching and evaporation techniques.

The silicon slices of n-type were etched in CP6 $\left(25 \% \mathrm{HF}, 25 \% \mathrm{CH}_{3} \mathrm{COOH}\right.$, and $50 \% \mathrm{HNO}_{3}$ ) for 3 min and quenched in distilled water. After the etch they were stored for a period of about $24 \mathrm{hs}$ after which the evaporations were performed at a pressure of $10^{-5}$ torr.

Three different structures were investigated:

1) Si-surface,

2) $\mathrm{Si}-\mathrm{Au}$, evaporation rate $50-100 \AA / \mathrm{min}$, and

3) $\mathrm{Si}-\mathrm{Ge}-\mathrm{Au}$ (evaporation rate $\mathrm{Ge}, 200 \AA / \mathrm{min}$ and $\mathrm{Au}$ as above).

The structures were made on the same slice with standard masking techniques (fig. 1). The analysis of the structures was performed about three days after the fabrication.

To calibrate the resonance yield for different oxygen contents, we fabricated a series of samples with well known oxide thicknesses from $30 \AA$ to $240 \AA$. The oxides formed were $\mathrm{Al}_{2} \mathrm{O}_{3}$ on $\mathrm{Al}$ plates in an anodizing bath. The method is described in ref. 9. The stochiometry of the formed oxides is $\left.\mathrm{Al}_{2} \mathrm{O}_{(3.05 \pm 0.05)}{ }^{10}\right)$. On top of the oxide layers, a gold 
layer was evaporated of the same thickness as the layers of structure (2) and (3).

\subsection{Measurements}

The experiments were performed at the Van de Graaff accelerator, Studsvik, Sweden, with standard backscattering equipment.

The ${ }^{16} \mathrm{O}(\alpha, \alpha)^{16} \mathrm{O}$ resonance yield has its maximum at a scattering angle of $180^{\circ}$ as displayed in fig. 2; this property determines the geometry of our experiment. A $300 \mathrm{~mm}^{2}$ annular surface barrier detector was used (resolution approximately $30 \mathrm{keV}$ for $3 \mathrm{MeV} \alpha$ ). A collimator of diameter $17 \mathrm{~mm}$ was placed in front of the detector, and the distance between collimator and target was measured to be $74 \mathrm{~mm}$. This arrangement corresponds to a backscattering angle of $113.5^{\circ}$ to $173.5^{\circ}$.

The resonance yield $(Y)$ was defined as the ratio of the oxygen peak area to the integrated area of $\mathrm{Al}$ or Si distribution between two fixed channels. This yield was determined in an energy scanning measurement, where the $\alpha$-energy was changed in steps of about $2.5 \mathrm{keV}$ over the resonance.

The resonance yield curves for the well determined aluminium oxide thicknesses are shown in fig. 3. Since in this case the resonance is broad compared to the energy spread of the beam (less than $1 \mathrm{keV}$ ) as well as the energy loss and straggling in the oxide layers (see insert of fig. 3) the yield at the maximum point in the scan is propor-

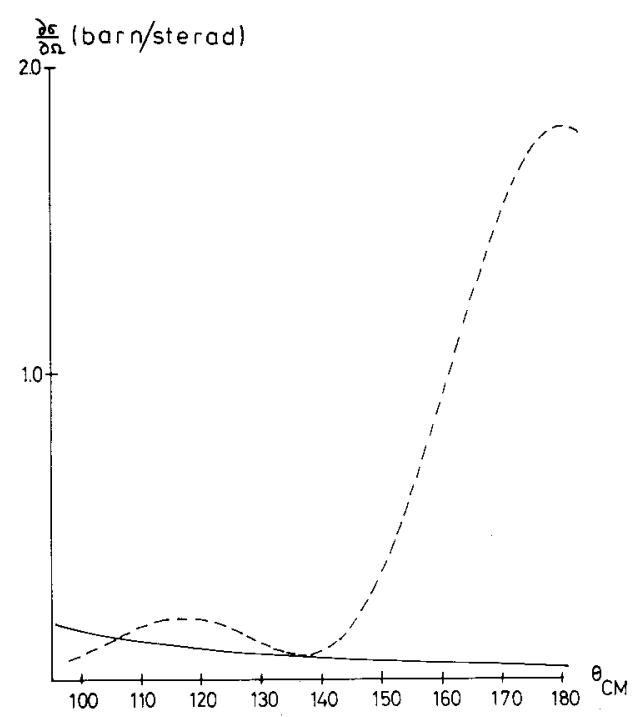

Fig. 2. The ${ }^{16} \mathrm{O}(\alpha, \alpha)^{16} \mathrm{O}$ differential scattering cross section at the resonance energy $3.045 \mathrm{MeV}$ as a function of scattering angle (dashed line) and the extrapolated Rutherford cross section (solid line) in c.m. coordinates.

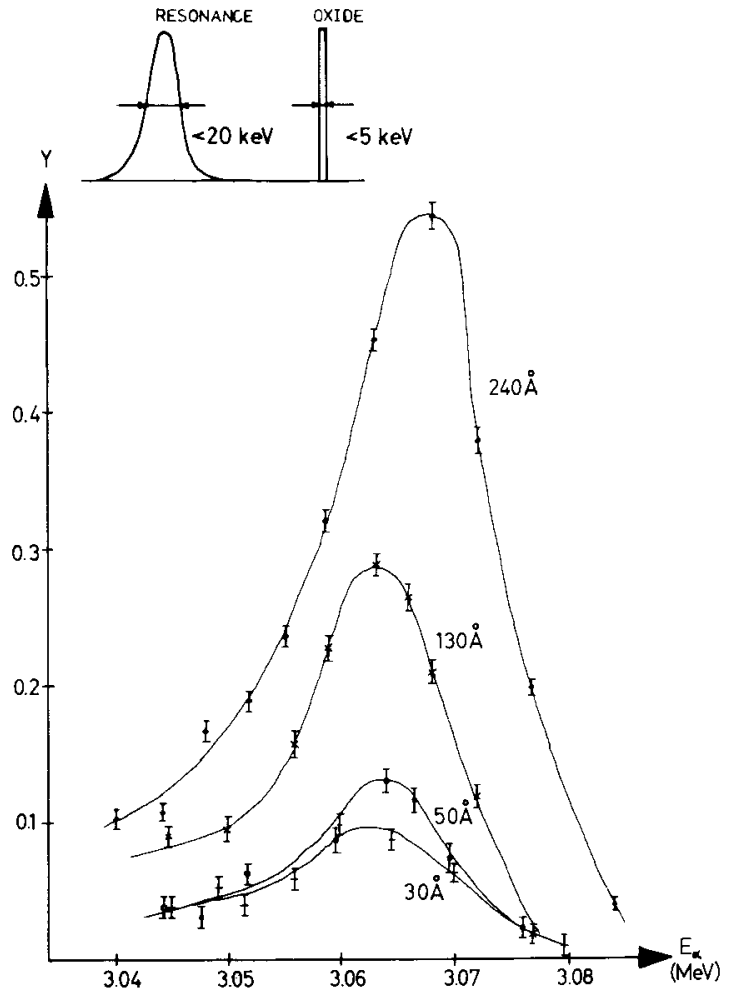

Fig. 3. Resonant alpha scattering yield $Y$ defined as the ratio of oxygen peak area to background for different anodized $\mathrm{Al}_{2} \mathrm{O}_{3}$ thicknesses on Al-foils as a function of acceleratorbeam energy. The shift in resonant energy to $3.065 \mathrm{MeV}$ is caused by the energy loss in the top $\psi$ Au layer.

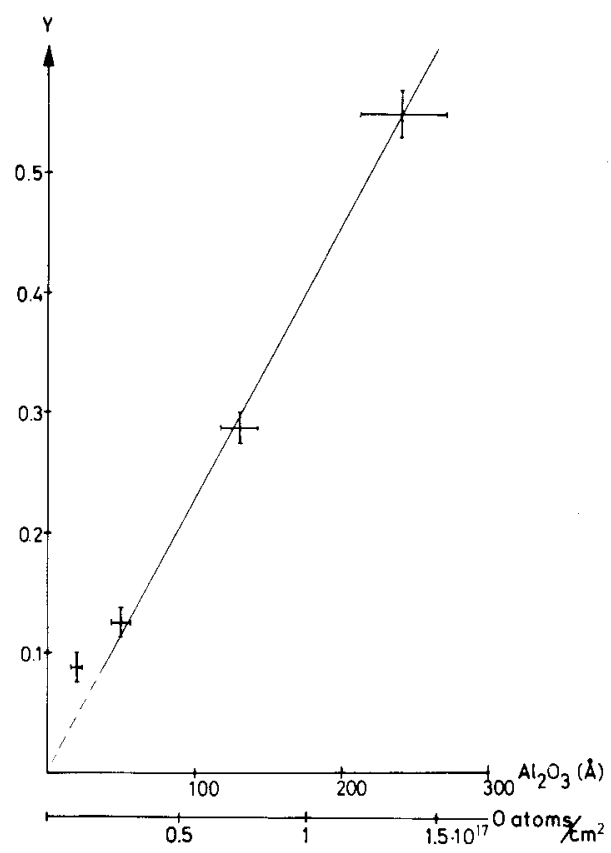

Fig. 4. Maximum of the resonance curves in fig. 3 as a function of $\mathrm{Al}_{2} \mathrm{O}_{3}$ thickness and oxygen content. 
tional to the oxygen content. Fig. 4 shows the result of the calibration procedure, where oxygen content as a function of maximum yield is plotted. The errors in the thickness values for the $\mathrm{Al}_{2} \mathrm{O}_{3}$ layer are indicated.

The deviations of the two lower points, corresponding to the $30 \AA$ and $50 \AA \mathrm{Al}_{2} \mathrm{O}_{3}$ layers, are probably caused by the tendency these layers have of increasing their oxide thickness when stored in air. (The layers were fabricated the day before the measurements.)

After the calibration, the layered structures were analyzed by a similar energy scan. At each energy set of the incoming beam, a spectum of the backscattered $\alpha$-particles was taken to determine the yield. In fig. 5 three spectra are shown for the different structures. Beam current was typically $5 \mathrm{nA}$
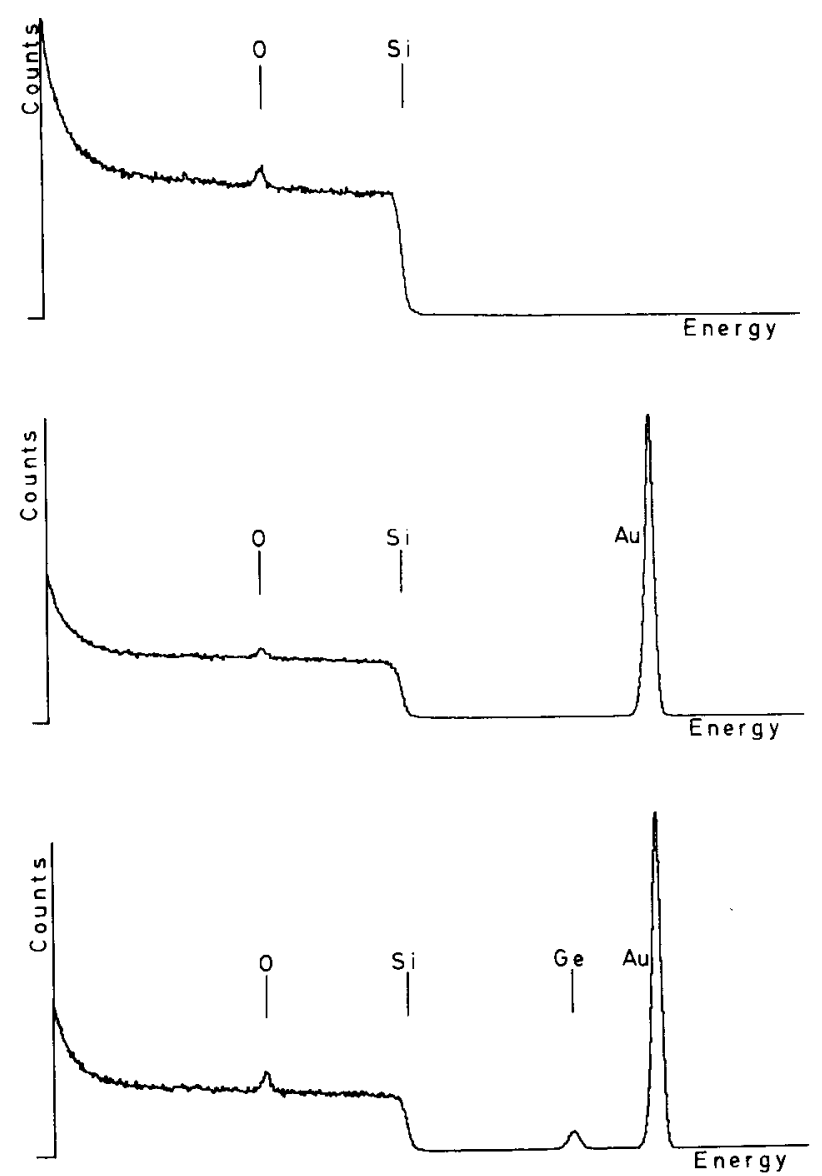

Fig. 5. Backscattering spectra at or near resonance for the three structures (from top) (1) Si-surface, (2) $\mathrm{Au}$ on $\mathrm{Si}$, and (3) Au$\mathrm{Ge}-\mathrm{Si}$ structure. The areas of the oxygen peaks in a spectra are proportional to oxygen content in a layer of thickness corresponding to the resonance width at the depth where the resonance occurs. to avoid pileup effects, and the collecting time at each energy was five to fifteen minutes.

From the backscattering spectra the content of $\mathrm{Ge}$ and $\mathrm{Au}$ was calculated with standard RBS methods ${ }^{11}$ ).

\section{Results and discussion}

In fig. 6 are shown the results of the energy scans performed on sample 12 consisting of the three structures as shown in fig. 1. The Si-substrate is $100 \Omega \cdot \mathrm{cm}$ n-type material.

The thicknesses of the evaporated layers were measured from the spectra shown in fig. 5 to be $350 \AA$ and $100 \AA \mathrm{Ge}$ (assuming bulk densities). The corresponding energy losses are indicated in fig. 6 for sample C. (Energy loss data from ref. 12 are used.). The resonance yield of the bare silicon surface indicates an oxide thickness of about $30 \AA$ (if stochiometric $\mathrm{SiO}_{2}$ is assumed).

The yield curve from the $\mathrm{Au}-\mathrm{Si}$ and $\mathrm{Au}-\mathrm{Ge}-\mathrm{Si}$ structures has been analysed semi-quantitatively with the resonance cross section $\sigma(E)$ given in ref. 8 applied on different assumed oxygen distributions. A comparison of the experimentally obtained yield curve and the theoretically calculated curves has then given us a semi-quantitative picture of the oxygen distributions in the layers. In the $\mathrm{Si}-\mathrm{Au}$ case we found that the oxygen content at the silicon-gold interface is of the same order as before the gold evaporation, but there is a more or less continuous oxygen distribution throughout the gold layer: total amount about $1 \times 10^{16}$ at-

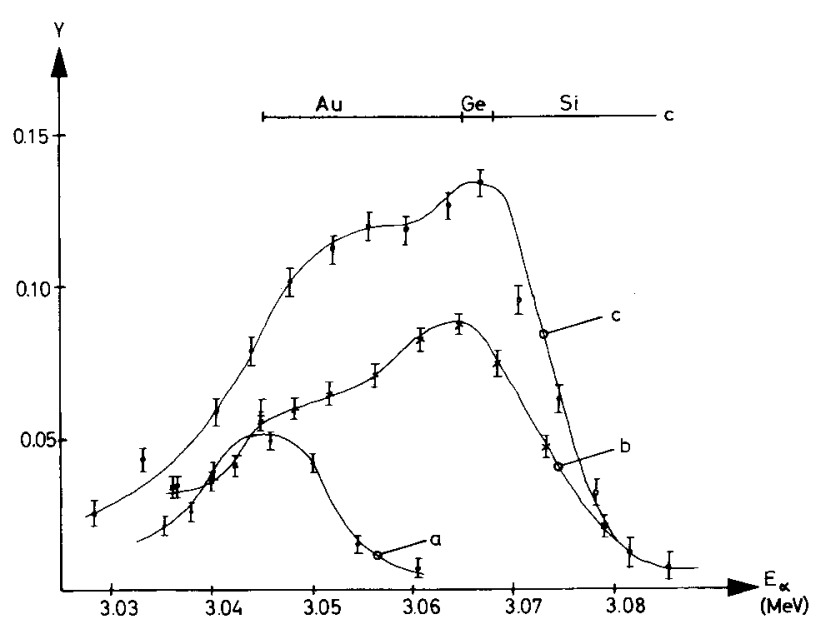

Fig. 6. Energy scan of the structures (a) Si-surface, (b) $340 \AA$ $\mathrm{Au}$ on $\mathrm{Si}$, and (c) $340 \AA \mathrm{Au}$ and $100 \AA \mathrm{Ge}$ on Si. 
$\mathrm{oms} / \mathrm{cm}^{2}$. In the $\mathrm{Ge}-\mathrm{Au}-\mathrm{Si}$ structure, it was found that the oxygen content in the Ge-layer and the oxygen content at the $\mathrm{Si}$ surface add up to about $1.6 \times 10^{16}$ atoms $/ \mathrm{cm}^{2}$. The oxygen content in the gold bulk and on the gold surface has increased compared to structure (2). The increase of oxygen because of the added germanium layer is probably from a slight oxidation during the evaporation of the germanium and on an oxidation of the Ge surface during the vacuum break before the Au-evaporation.

These preliminary results show a promising analytical technique that could be applied to semiconductor technology and metallurgy. A detailed analysis of oxygen contents in layered structures prepared under various conditions is in progress. To enhance sensitivity and accuracy a goniometer for alignment of the silicon substrate will be used, permitting channeling.

This work was supported by the Swedish National Science Research Council. The authors wish to thank Prof. P.A. Tove and Prof. A. Many for valuable discussions. We are also indebted to $\mathrm{L}$.
Norell and the staff at the Van de Graaff laboratory, Studsvik for the good working conditions.

\section{References}

1) K. Eisele and M. Schulz, Int. Symp. on Vacuum and thin film technology, Uppsala (1976) to be publised in Vacuum).

2) S. Kar and W. E. Dahlke, Sol. Electron. 15 (1972) 869.

3) N. J. Hansen, R. G. Scott and D. J. Henderson, Nucl. Instr. and Meth. 104 (1972) 333.

4) W. K. Chu, J. W. Mayer, M--A. Nicolet, G. Amsel, T. Buck and F. Eisen, Thin Solid Films 17 (1973) 1.

5) G. Amsel, J. P. Nadai, E. D. Artemare, D. David, E. Girard and J. Moulin, Nucl. Instr. and Meth. 92 (1971) 481.

6) G. Dearnaley, P. D. Goode, W. S. Miller and J. F. Turner, Ion implantation in semiconductors and other materials (ed. B. L. Crowder; Plenum Press, New York, 1973) p. 405.

7) A. Turos, L. Wielunski and A. Barcz, Nucl. Instr. and Meth. 111 (1973) 605.

8) G. Mezey, J. Gyulai, T. Nagy, E. Kotai and A. manuba, Ion beam surface layer analysis, (eds. O. Meyer, G. Linker and F. Käppeler; Plenum Press, New York, 1976) p. 303.

$\left.{ }^{9}\right)$ J. A. Davies, J. Friesen and J. D. McIntyre, Can. J. Chem. 38 (1960) 1526.

10) A. L'Hoir, C. Cohen and G. Amsel, ibid., p. 965.

11) W. K. Chu, New uses of ion accelerators (ed. J. F. Ziegler; Plenum Press, New York, 1975) p. 135

12) J. F. Ziegler and W. K. Chu, At. Data Nucl. Data Tables 13 (1974) 463. 